\title{
Simulation of Outer Rotor Permanent Magnet Brushless DC Motor Using Finite Element Method for Torque Improvement
}

\author{
Uma Devi Kumaravelu' ${ }^{1}$ and Sanavullah Mohamed Yakub ${ }^{2}$ \\ ${ }^{1}$ EEE Department, Sengunthar Engineering College, Tiruchengode 637205, India \\ ${ }^{2}$ EEE Department, VMKV Engineering College, Salem 636308, India \\ Correspondence should be addressed to Uma Devi Kumaravelu, kindlyuma@yahoo.co.in
}

Received 18 February 2012; Revised 20 April 2012; Accepted 22 April 2012

Academic Editor: Jing-song Hong

Copyright (C) 2012 U. D. Kumaravelu and S. Mohamed Yakub. This is an open access article distributed under the Creative Commons Attribution License, which permits unrestricted use, distribution, and reproduction in any medium, provided the original work is properly cited.

\begin{abstract}
A method of simulation and modeling outer rotor permanent magnet brushless DC (ORPMBLDC) motor under dynamic conditions using finite element method by FEMM 4.2 software package is presented. In the proposed simulation, the torque developed at various positions of the rotor, under a complete cycle of excitation of the stator, is analysed. A novel method of sinusoidal excitation is proposed to enhance the overall torque development of ORPMBLDC motor.
\end{abstract}

\section{Introduction}

The impressive improvement in power electronic switching devices, integrated circuits, developments and refinements in permanent-magnetic materials, and manufacturing technology have led to the development of brushless permanentmagnet motors that offer significant improvements in power density, efficiency, and noise reduction [1]. Brushless permanent-magnet motors are especially demanded in clean and explosive environments such as aeronautics, robotics, food and chemical industries, electric vehicles, medical instruments, and computer peripherals [2-4]. PM D.C. brushless motors use direct feedback of the rotor angular position so that the input armature current can be switched, among the motor phases, in exact synchronism with the rotor motion. This concept is known as self-controlled synchronization or electronic commutation. The electronic inverter and position sensors are equivalent to the mechanical commutator in D.C. motors [4].

There are several reasons for the overwhelming prevalence of motors having inner rotors [3]. These reasons include the ease of heat removal, because the windings are on the outside, and the containment of the rotating element. In some applications, these attributes are not as important as the benefits gained from having an outer rotor and inner stator. Motors having this construction are sometimes called inside-out motors. Outer rotor motors appear most commonly as spindle motors for hard disk drives and as the drive motor for ventilation fans, water pumps, powerassisted steering such as those used to cool CPUs and computer cases. In these applications, the motor becomes an integrated part of a larger structure. Although individual magnets can be used in outer rotor motors, it is common to use a single-bonded magnet ring inside a rotor. Since the stator teeth point outward, this motor is relatively easy to wind. For a given outer radius, an outer rotor motor has a much larger air gap radius than that of an inner rotor motor. As a result, higher torque is achievable, provided the ohmic losses of the stator windings can be dissipated [5-7].

The finite element method (FEM) has proved to be particularly flexible, reliable, and effective in the analysis and synthesis of power-frequency electromagnetic and electromechanical devices. Even in the hands of non-specialists, modern FEM packages are user friendly and allow for calculating the electromagnetic field distribution and integral parameters without detailed knowledge of applied mathematics. The FEM can analyze PM circuits of any shape and material. There is no need to calculate reluctances, leakage factors, or the operating point on the recoil line. The PM demagnetization curve is input into the finite element program which can calculate the variation of the magnetic flux density throughout the PM system. An important advantage 
of finite element analysis over the analytical approach to PM motors is the inherent ability to calculate accurately armature reaction effects, inductances and the electromagnetic torque variation with rotor position (cogging torque) [5, 8-10]. In electrical machine problems four methods of calculating forces or torques are used: the Maxwell stress tensor, the coenergy method, the Lorentz force equation, and the rate of change of field energy method. The most appropriate method is usually problem dependent, although the most frequently used is the Maxwell stress tensor method [11].

FEMM package is an open source, simple, accurate, and low computational cost freeware product, popular in science and engineering. Several applications in areas such as Electromagnetics, Materials Science, Industry, Medicine, Experimental and Particle Physics, Robotics, Astronomy, and Space Engineering can be found. The software is reasonably fast and accurate, user friendly, and freely distributed. The last seems to be its main advantage concerning its educational value. Its capability to meet as a complementary tool the needs of teaching electromagnetic in higher education will be explored and evaluated [12].

In the proposed model FEMM 4.2 software package has been used to investigate the excitation currents to the different phases of stator windings and corresponding torque developed to enhance the torque produced by ORPMBLDC Motors.

\section{Mathematical Modeling}

The most frequently used methods are the Maxwell stress tensor; the use of the Maxwell stress tensor is simple from a computational perspective, since it requires only the local flux density distribution along specific line or contour. Using the definition of Maxwell stress tensor, the electromagnetic forces can be determined on the basis of the magnetic flux density, that is:

the total force:

$$
\vec{F}=\iint\left[\frac{1}{\mu_{0}} \vec{B}(\vec{B} \cdot \vec{n})-\frac{1}{2 \mu_{0}} B^{2} \vec{n}\right] d s,
$$

the normal force:

$$
F_{n}=\frac{1}{2 \mu_{0}} \int\left[B_{n}^{2-} B_{t}^{2}\right] d l,
$$

the tangential force:

$$
F_{t}=\frac{L_{i}}{\mu_{0}} \int B_{n} B_{t} d l
$$

where $\vec{n}, L_{i}, l, B_{n}$, and $B_{t}$ are the normal vector to the surface $S$, stack length, integration contour, radial (normal) component to the magnetic flux density and tangential component of the magnetic flux density, respectively.

The torque $\vec{T}=\vec{r} \times \vec{F}$ in connection with (3) is

$$
T=\frac{L_{i}}{2 \mu_{0}} \oint r B_{n} B_{t} d l,
$$

where $r$ is the radius of the circumference which lies in the air gap. since a finite grid is being used, the previous equations can be written for element $i$. The torque shown below in cylindrical coordinates is a sum of torques for each element $i$, that is:

$$
T=\frac{L_{i}}{\mu_{0}} \sum r^{2} \int_{\theta_{i}}^{\theta_{i+1}} B_{r i} B_{\theta i} d \theta .
$$

The accuracy of this method is markedly dependent on the model discretization and on the selection of the integration line or contour. The Maxwell stress tensor line integration necessitates a precise solution in the air gap, demanding a fine discretization of the model in the air gap since the flux density is not continuous at the nodes and across boundaries of first-order elements [13].

\section{Modeling of ORPMBLDC Motor by FEMM}

Finite element method magnetic (FEMM 4.2) is the software package has been used to model the ORPMBLDC motor. FEMM 4.2 is a suite of programs for solving low frequency electromagnetic problems on two-dimensional planar and axisymmetric domains. The program currently addresses linear/nonlinear magnetostatic problems, linear/nonlinear time harmonic magnetic problems, linear electrostatic problems, and steady-state heat flow problems.

FEMM 4.2 is divided into three parts: Interactive shell (femm.exe). This program is a multiple document interface preprocessor and a post-processor for the various types of problems solved by FEMM4.2. It contains a CAD-like interface for laying out the geometry of the problem to be solved and for defining material properties and boundary conditions. AutoCAD DXF files can be imported to facilitate the analysis of existing geometries [12]. Field solutions can be displayed in the form of contour and density plots. The program also allows the user to inspect the field at arbitrary points, as well as evaluate a number of different integrals and plot various quantities of interest along user-defined contours triangle.exe. Triangle breaks down the solution region into a large number of triangles, a vital part of the finite element process. Each solver takes a set of data files that describe problem and solve the relevant partial differential equations to obtain values for the desired field throughout the solution domain. The Lua scripting language is integrated into the interactive shell. Unlike previous versions of FEMM (i.e., v3.4 and lower), only one instance of Lua is running at any one time. This single instance of Lua can both build and analyze geometry and evaluate the postprocessing results, simplifying the creation of various sorts of "batch" runs. In addition, all edit boxes in the user interface are parsed by Lua, allowing equations or mathematical expressions to be entered into any edit box in lieu of a numerical value. In any edit box in FEMM 4.2, a selected piece of text can be evaluated by Lua via a selection on the right mouse button menu.

The motor with specifications given in Table 1 is modeled by FEMM package Version 4.2. Here the permanent magnets of outer rotor material property are chosen as ALNICO 8 and 


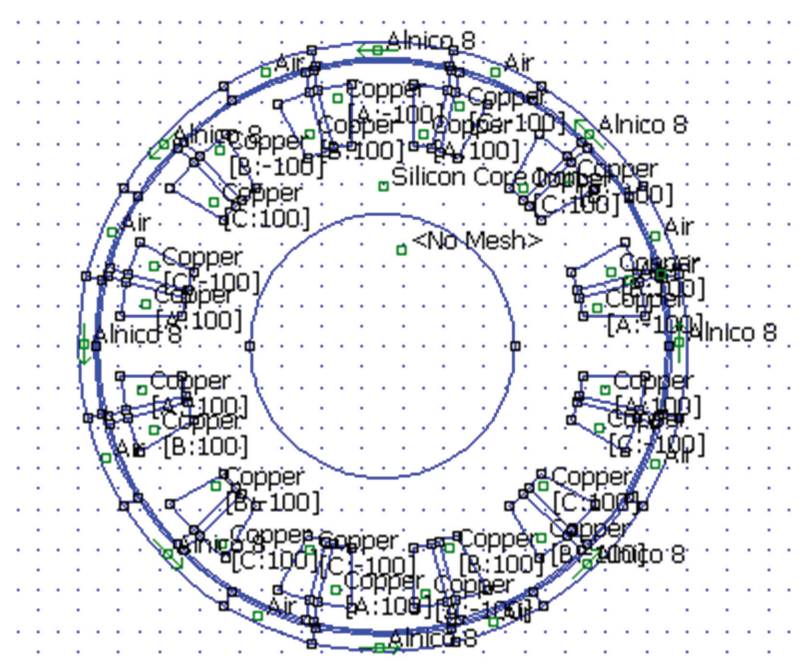

FIgURE 1: Motor model.

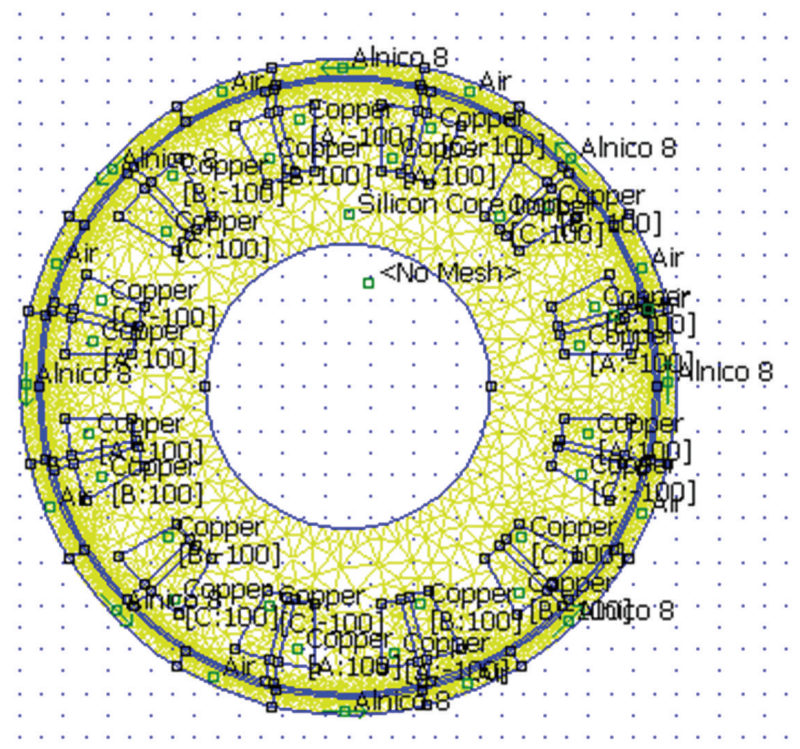

Figure 2: Fem meshed 2D model.

TABle 1: Motor specifications.

\begin{tabular}{lc}
\hline Outer rotor radius & $15 \mathrm{~mm}$ \\
Stator radius & $14 \mathrm{~mm}$ \\
Air gap & $.2 \mathrm{~mm}$ \\
Rotor pole & 8 \\
Stator slots & 12 \\
\hline
\end{tabular}

stator with silicon core iron. Material properties chosen for various components are detailed in Table 2. The developed ORPMBLDC motor model has been shown in Figure 1; stator windings are excited by three phases, namely A, B, and C. electromagnetic properties of the three phase windings.

The motor has been modeled with 5894 nodes and11419 elements by $2 \mathrm{D}$ planar $1 \mathrm{~mm}$ depth which is shown in

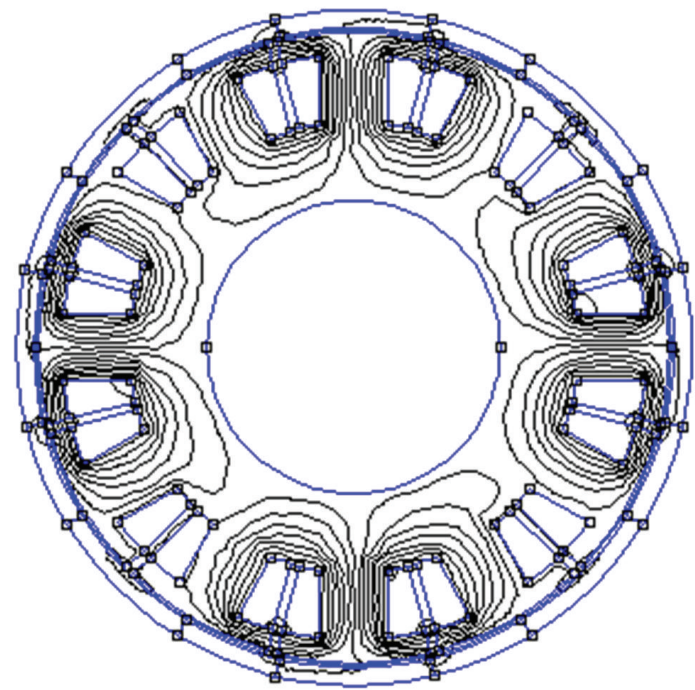

Figure 3: Flux plot.

TABLE 2: Material properties.

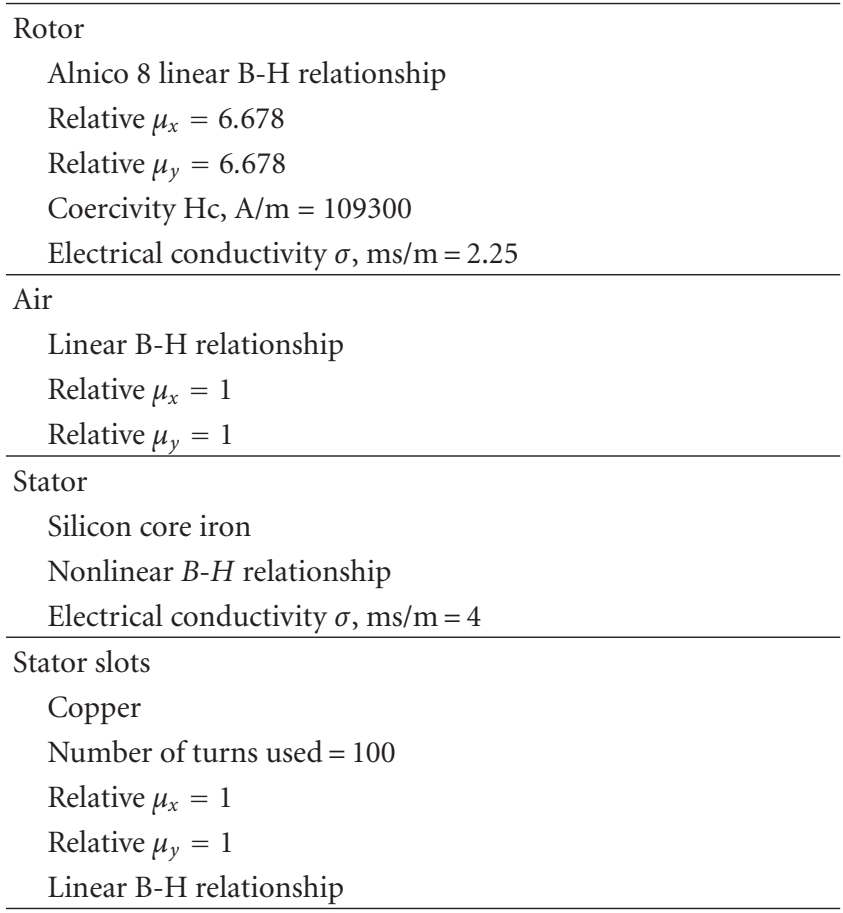

Figure 2. Flux lines established, and flux density distribution for the given excitation in three phases is shown in Figures 3 and 4 , respectively. Here stator and rotor have been modeled by using magnetic materials using silicon core iron and ALNICO, respectively, and these materials' B-H characteristics have been shown in Figures 5 and 6.

\section{Lua Scripting Implementation}

The Lua extension language has been used to add scripting/batch processing facilities to FEMM. The interactive shell 

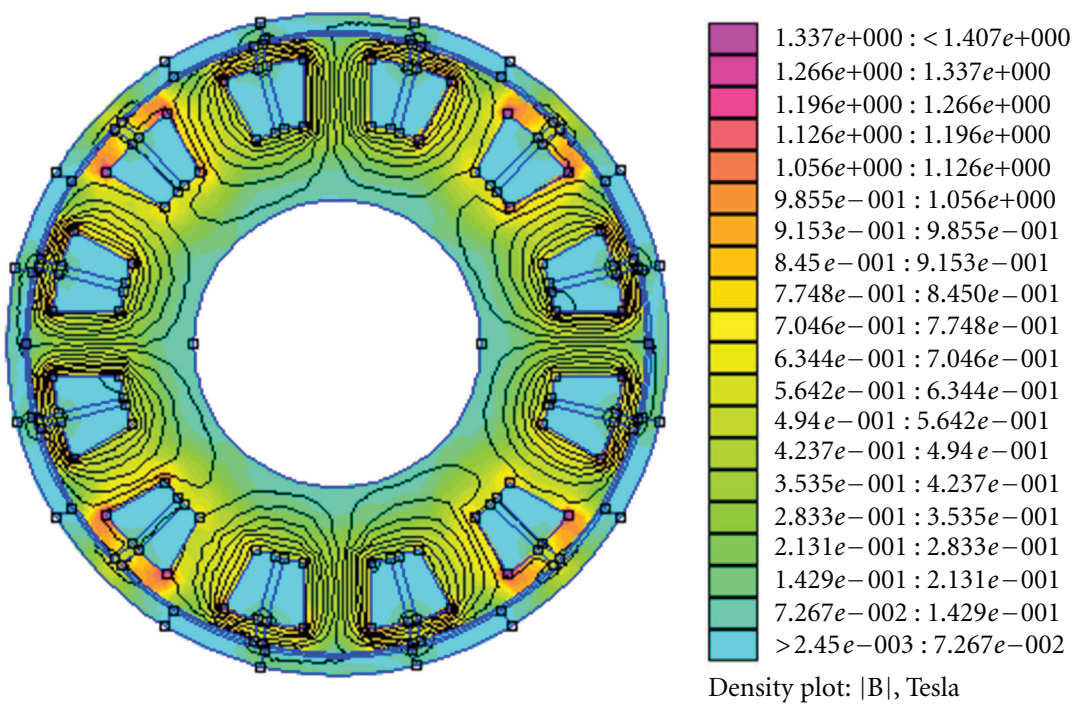

FIGURE 4: Magnetic flux density distribution.

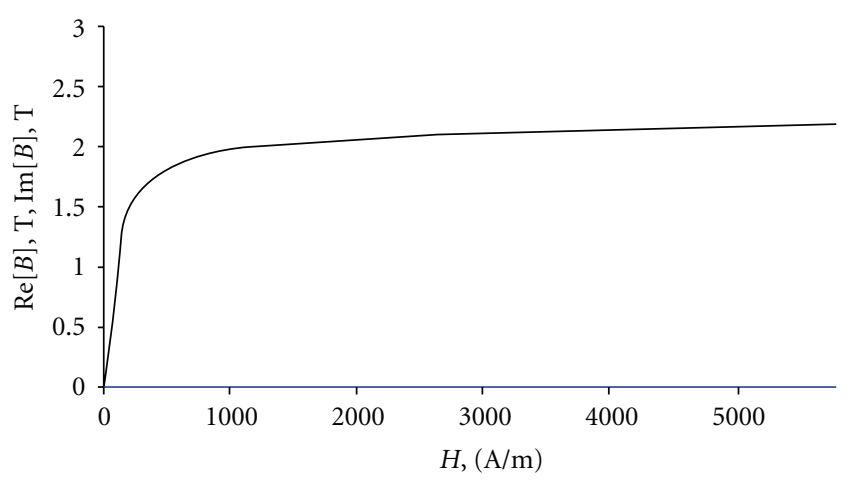

$\operatorname{Re}[B], \mathrm{T}$

$\operatorname{Im}[B], \mathrm{T}$

Figure 5: Rotor linear B-H relationship.

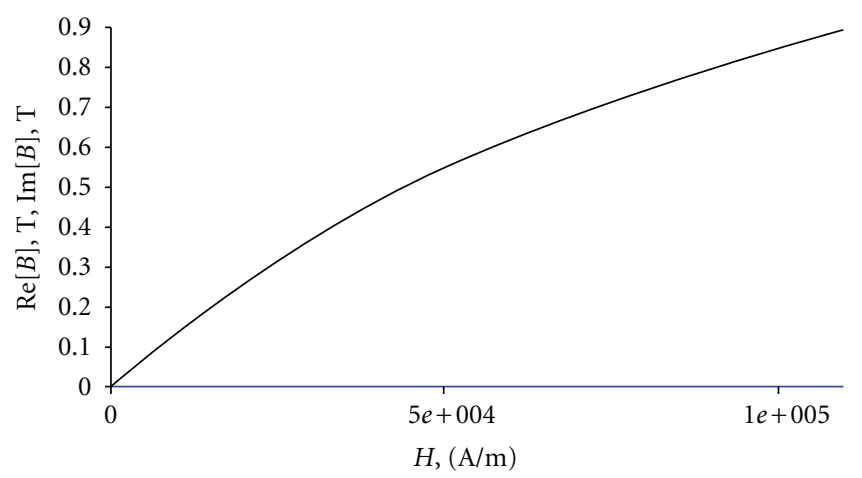

$\operatorname{Re}[B], \mathrm{T}$

$\operatorname{Im}[B], \mathrm{T}$

FIgURE 6: Stator nonlinear B-H relationship. can run Lua scripts through the Open Lua Script selection on the Files menu, or Lua commands can be entered in directly to the Lua Console Window. Lua is a complete, opensource scripting language. Source code for Lua, in addition to detailed documentation about programming in Lua, can be obtained from the Lua homepage at http://www.lua.org. Because the scripting files are text, they can be edited with any text editor (e.g., notepad). As of this writing, the latest release of Lua is version 5.0. However, the version of Lua incorporated into FEMM is Lua 4.0. In addition to the standard Lua command set described, a number of FEMMspecific functions have been added for manipulating files in both the pre- and postprocessor.

\section{Results and Discussions}

The developed motor model is discretised into 5894 nodes and 11419 elements by using FEMM 4.2 software package. The three-phase stator windings are excited by phase currents $\mathrm{A}, \mathrm{B}$, and $\mathrm{C}$ by varying the phase angles from $0^{\circ}$ to $360^{\circ}$ with interval of 5 , that is, totally 73 iterations for each rotor position. The corresponding torque values are investigated. This procedure is repeated for rotor angles from $0^{\circ}$ to $90^{\circ}$ with an increment of $2.5^{\circ}$. Torque for various phase angles from $0^{\circ}$ to $360^{\circ}$ with interval of 10 (for simplicity) for rotor at starting position at $00^{\circ}, 45^{\circ}$, and $87.5^{\circ}$ and Figures 7, 8, and 9, respectively. For each rotor position peak torque value is determined, and in total 36 rotor positions are studied for one quadrant. As the motor model is being axisymmetry, investigations are carried out for one quadrant. A plot between peak torque values and rotor angles has been obtained as in Figure 10. It is observed from the plot the torque developed by the ORPMBLDC motor can be improved to approach the ideal torque by designing the switching circuit to the motor drive to supply the phase 


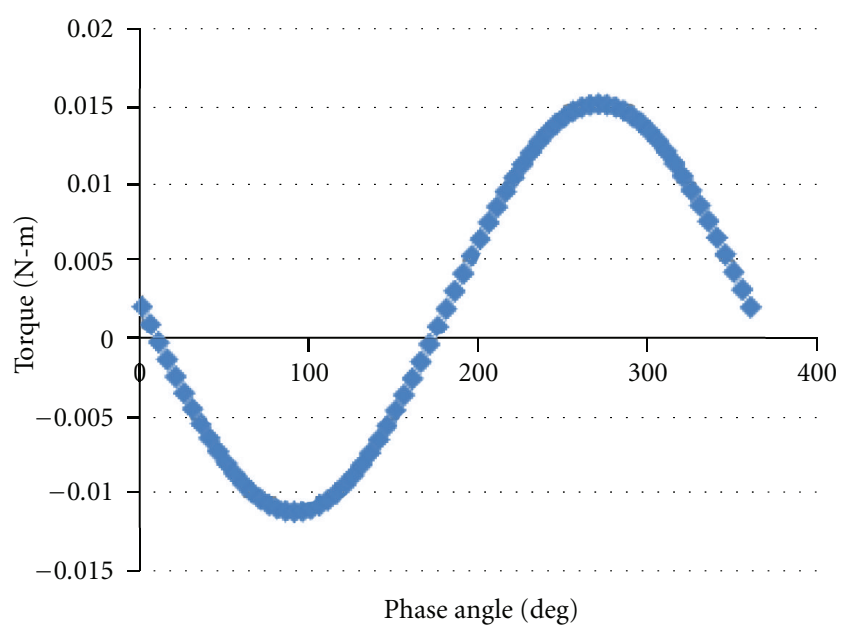

Figure 7: Rotor angle- $00^{\circ}$ : phase angle versus torque.

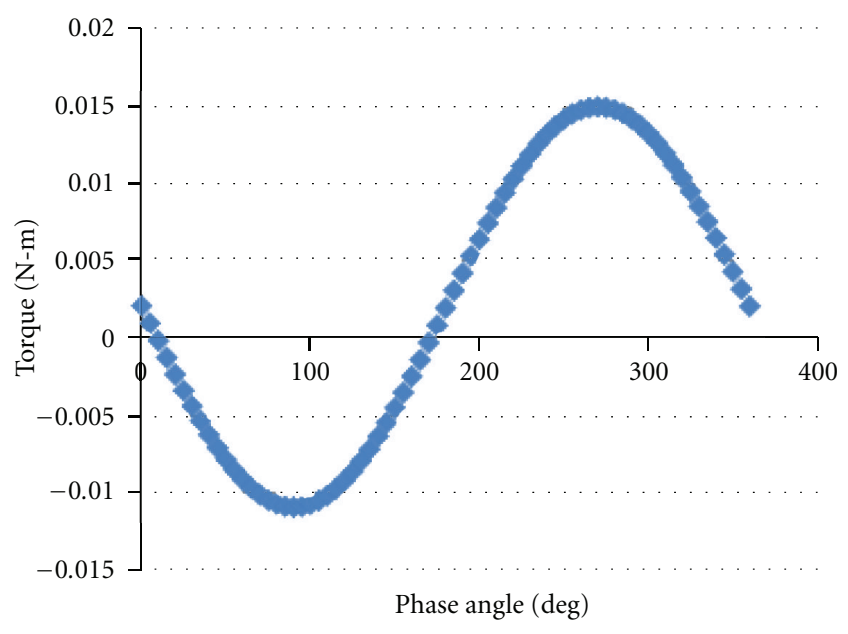

FigURE 8: Rotor angle- $45^{\circ}$ : phase angle versus torque.

current to develop the maximum torque for particular rotor positions. The average torque developed will be the maximum for the particular machine and hence the output power. The efficiency of the motor will be maximum at any load.

\section{Conclusions}

FEMM package is useful software to solve any electromagnetic problems. It is concluded that from the FEMM output the motor can be driven at its peak torque at any rotor position to drive the load connected by switching the excitation supply to the phase windings at phase angle for peak torque. This will lead to the maximum average torque for any load and maximum efficiency. It is possible nowadays with the impressive improvement in power electronic switching devices and integrated circuits.

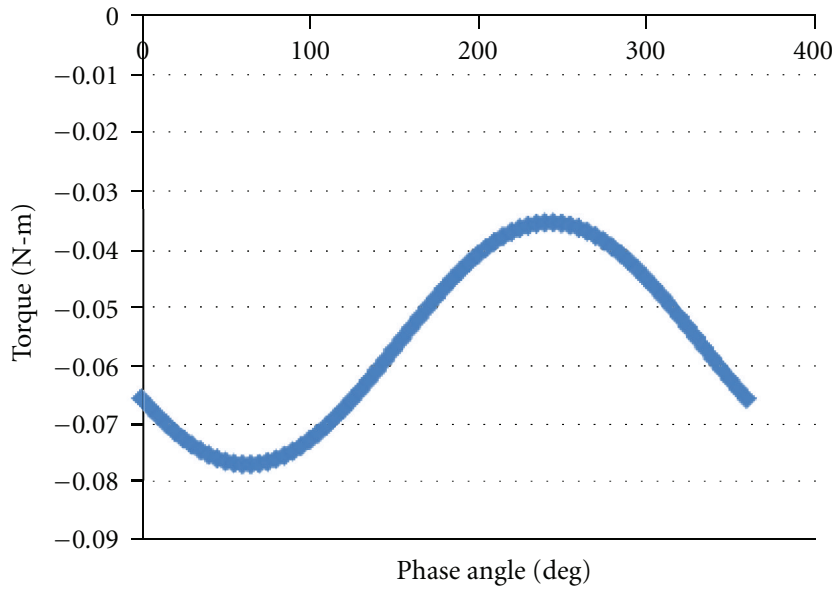

Figure 9: Rotor angle- $87.5^{\circ}$ : phase angle versus torque.

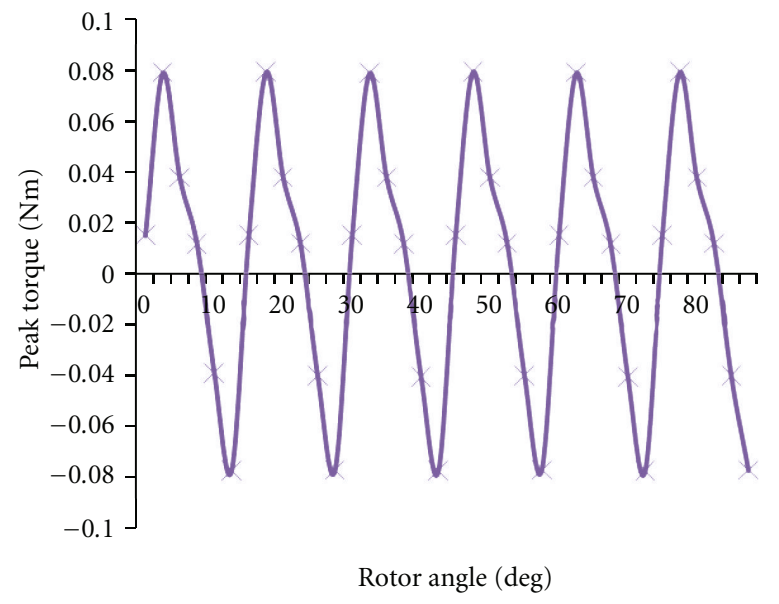

FIGURE 10: Rotor angle versus peak torque.

\section{References}

[1] J. Faiz, M. R. Azizian, and M. Aboulghasemian-Azami, "Simulation and analysis of brushless DC motor drives using hysteresis, ramp comparison and predictive current control techniques," Simulation Practice and Theory, vol. 3, no. 6, pp. 347-363, 1996.

[2] A. Pages, G. Lacombe, F. Marion, X. Brunotte, and R. Le Letty, "Upgrade of miniature out runner brushless DC motors," in Proceedings of the 11th International Conference on New Actuators (ACTUATOR'08), Bremen, Germany, June 2008.

[3] Ł. Knypiński, "The steady-state and transient FEM analysis of the outer rotor permanent magnet brushless DC motor," in Proceedings of the X International PhD Workshop (OWD'08), pp. 18-21, Poznan University of Technology, Wisla, Poland, October 2008.

[4] S. Rajagopalan, W. le Roux, T. G. Habetler, and R. G. Harley, "Dynamic eccentricity and demagnetized rotor magnet detection in trapezoidal flux (Brushless DC) motors operating under different load conditions," IEEE Transactions on Power Electronics, vol. 22, no. 5, pp. 2061-2069, 2007.

[5] D. Hanselman, Brushless Permanent Magnet Motor Design, Magna physics publishing, 2nd edition, 2006. 
[6] A. Kapun, M. Čurkovič, A. Hace, and K. Jezernik, "Identifying dynamic model parameters of a BLDC motor," Simulation Modelling Practice and Theory, vol. 16, no. 9, pp. 1254-1265, 2008.

[7] U. K. Madawala and J. T. Boys, "Magnetic field analysis of an ironless brushless dc machine," IEEE Transactions on Magnetics, vol. 41, no. 8, pp. 2384-2390, 2005.

[8] E. N. C. Okafor, P. E. Okon, and C. C. Okoro, "Magnetic field mapping of a direct current electrical machine using finite element method," Journal of Applied Sciences Research, vol. 5, no. 11, pp. 1889-1898, 2009.

[9] K. B. Baltzis, "The FEMM package: a simple, fast, and accurate open source electromagnetic tool in science and engineering," Journal of Engineering Science and Technology Review, vol. 1, no. 1, pp. 83-89, 2008.

[10] M. V. K. Chari and S. J. Salan, Numerical Methods in Electromagnetism, Academic Press, New York, NY, USA, 2000.

[11] A. Kostaridis, C. Soras, and V. Makios, "Magnetostatic analysis of a brushless DC motor using a two-dimensional partial differential equation solver," Computer Applications in Engineering Education, vol. 9, no. 2, pp. 93-100, 2001.

[12] K. B. Baltzis, "The finite element method magnetics (FEMM) freeware package: may it serve as an educational tool in teaching electromagnetics?" Education and Information Technologies, vol. 15, no. 1, pp. 19-36, 2010.

[13] J. F. Gieras and M. Wing, Permanent Magnet Motor Technology: Design and Applications, Marcel Dekker, New York, 2nd edition, 2002. 

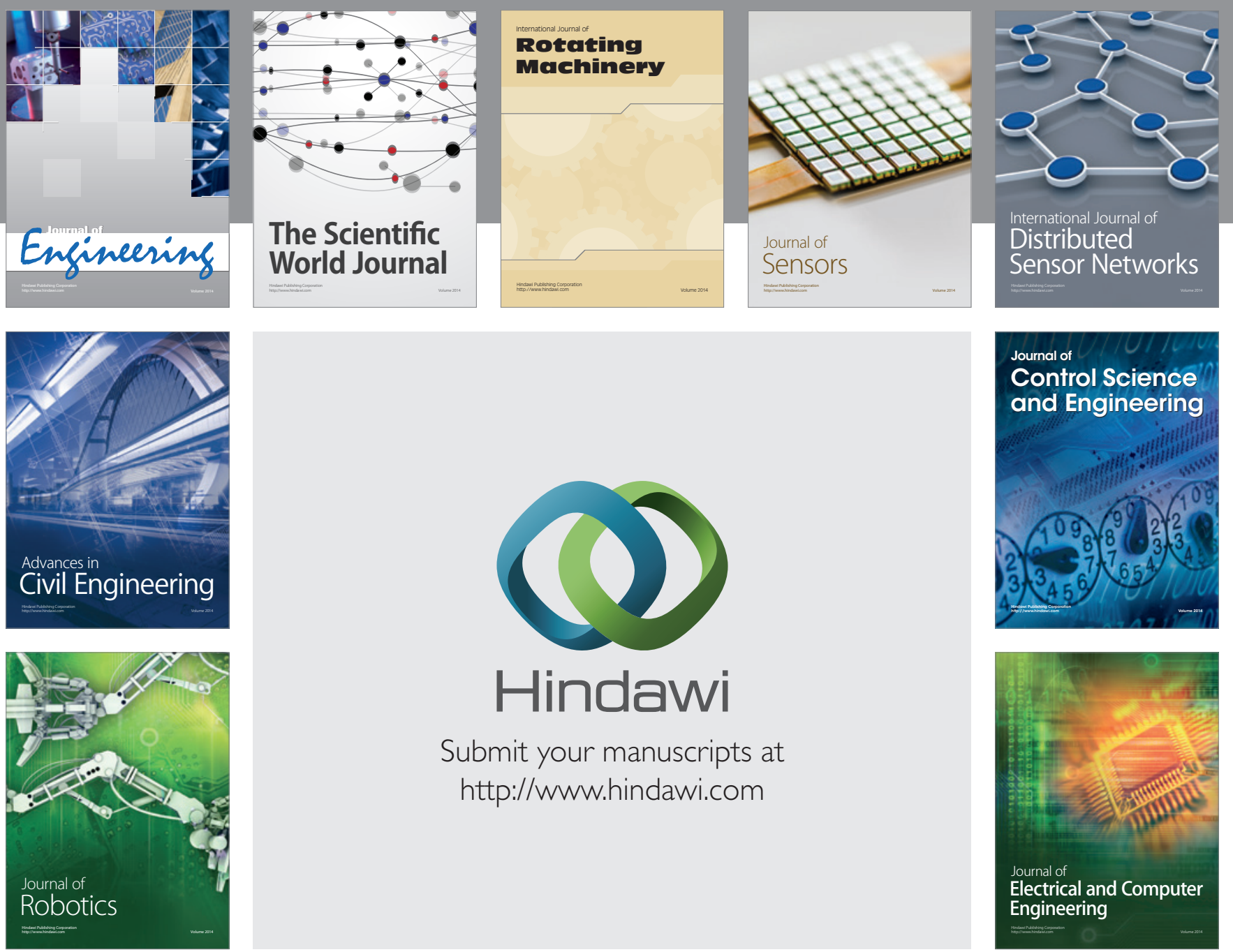

Submit your manuscripts at

http://www.hindawi.com
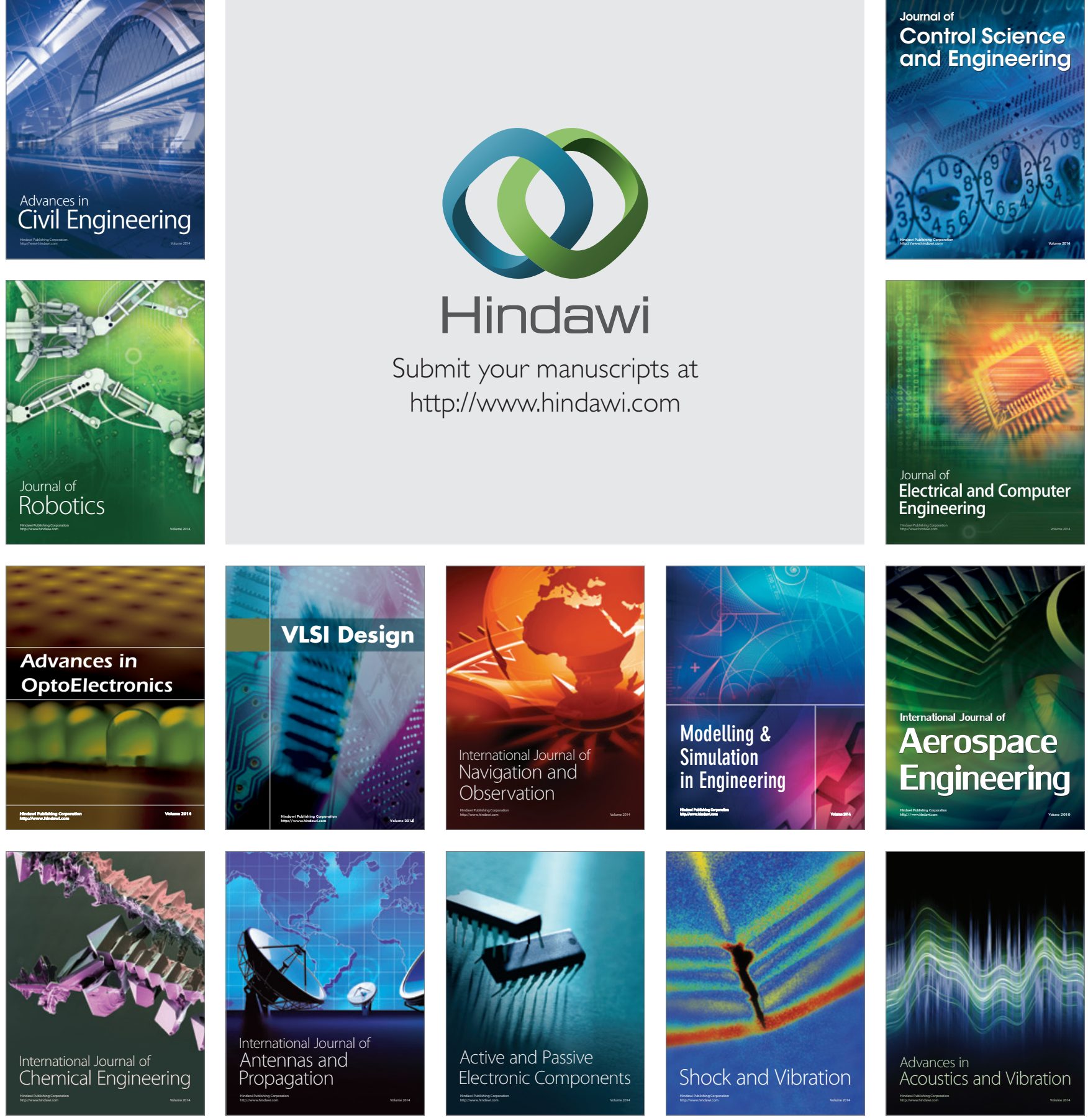